\section{A case of recurrent palpitations with wide complex tachycardia}

\section{CLINICAL INTRODUCTION}

A 50-year-old woman with recurrent episodic palpitations presented with hypotension to the emergency department. Her past medical history was inconsequential other than the use of $\beta$-blockers for occasional palpitations. A 12-lead surface ECG was taken (figure $1 \mathrm{~A}$ ) and the patient was subsequently cardioverted with $200 \mathrm{~J}$ to sinus rhythm (figure 1B). Her biochemical investigations and transthoracic echocardiogram were within normal limits.

\section{QUESTION}

Identify the tachycardia and findings in post-cardioversion sinus rhythm ECG (figure 1)?

1. Ventricular tachycardia and sinus rhythm with right bundle branch block

2. Ventricular tachycardia and sinus rhythm showing inferior wall myocardial infarction

3. Antidromic tachycardia and pre-excitation with left accessory pathway

4. Pre-excited atrial fibrillation and coronary sinus (CS) accessory pathway.
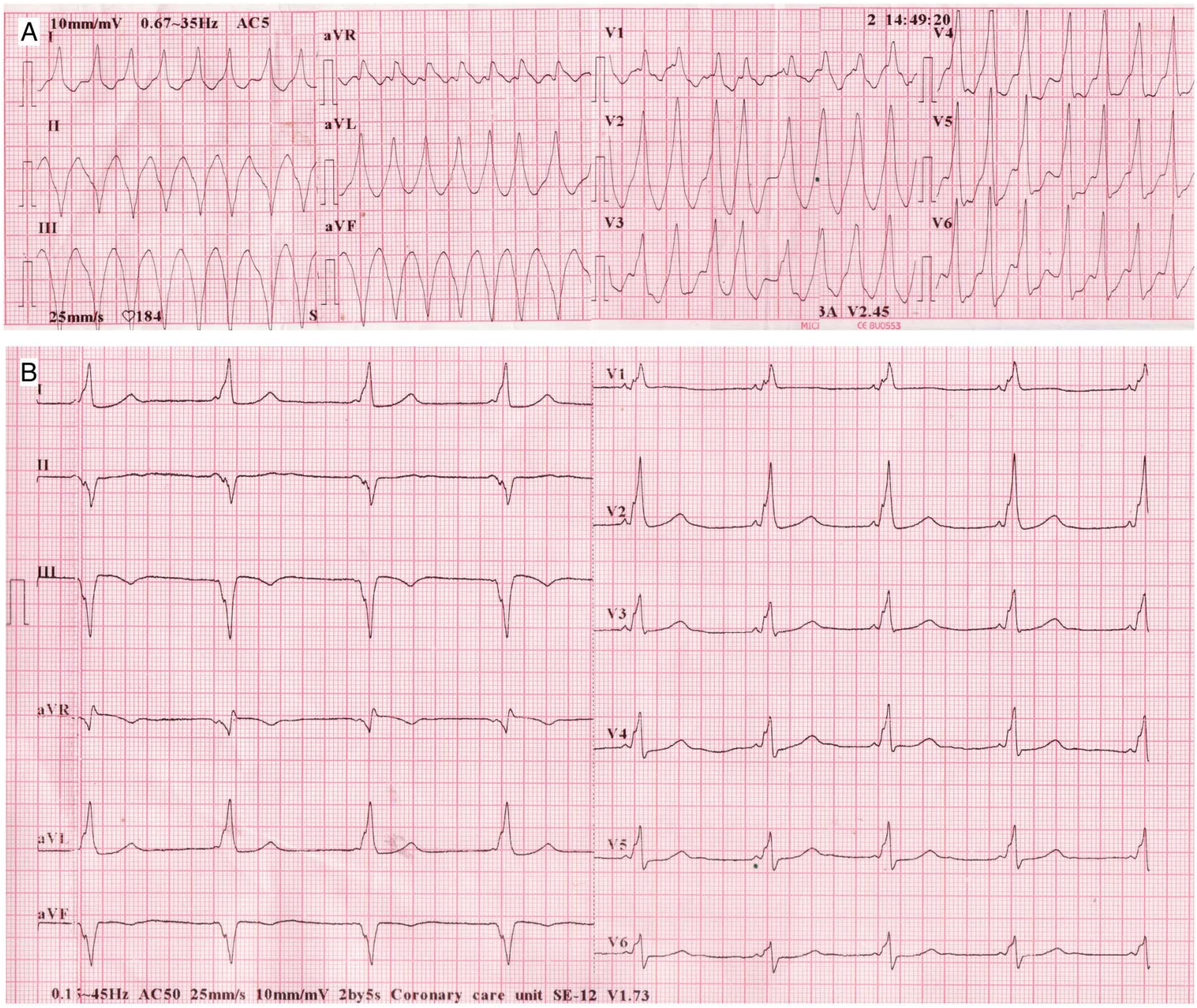

Figure 1 Surface ECG during admission (A) and post-cardioversion (B). 


\section{ANSWER}

The tachycardia on the ECG demonstrates an irregular rhythm at a rate of 200 beats/min with absent $P$ waves and wide QRS complexes suggestive of pre-excited atrial fibrillation (option 4). The post-cardioversion surface ECG revealed sinus rhythm, a short PR interval with wide QRS, 'pseudo infarct pattern' with negative $\delta$ in lead II, and a prominent $S$ wave in V6 representative of a typical CS accessory pathway activation. ${ }^{1}$ During the electrophysiology study, CS venography from the right internal jugular vein access with an Amplatz left catheter demonstrated an out-pouching near its ostium, indicative of diverticulum (see figure 2 and online supplementary video S1). Subsequently radiofrequency ablation at the neck of the diverticulum was efficient in abolishing atrioventricular conduction via the accessory pathway with disappearance of the $\delta$ wave from the surface ECG.

A varying cycle length during tachycardia, similar QRS axis during tachycardia and sinus rhythm, absence of capture and fusion beats makes ventricular tachycardia an unlikely diagnosis. Also, a right bundle branch block produces a delay in the terminal part of the QRS vector because of late right ventricular activation, making option 1 an incorrect choice. ${ }^{2}$ Though the surface ECG shows a QS pattern with T wave inversion in the inferior leads, an inferior wall myocardial infarction (option 2) is unlikely in this young patient with a normal echocardiogram

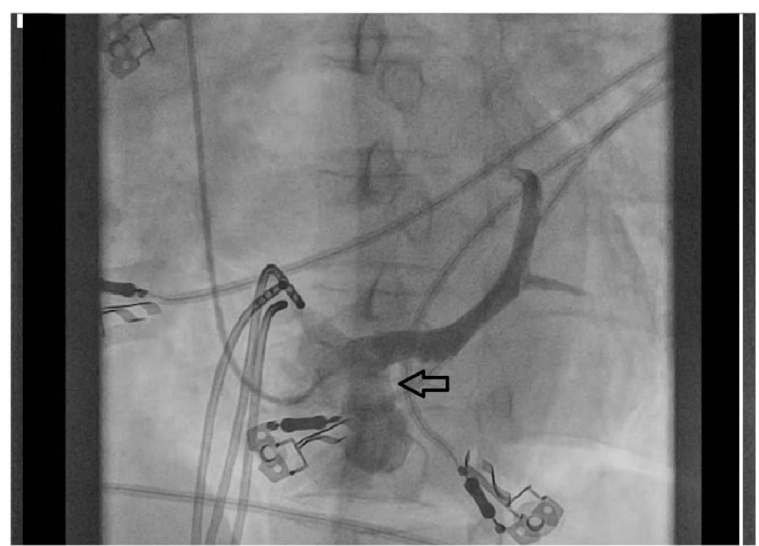

Figure 2 Coronary sinus venogram using an Amplatz left catheter in left anterior oblique view displaying a contrast filled diverticular sac adjacent to drainage of the coronary sinus into the right atrium. and no coronary risk factors or history of angina. An anterogradely conducting accessory pathway will have a constant rate and morphology of QRS complex during tachycardia and hence option 3 can be ruled out. ${ }^{3}$

Surface electrocardiography can be of assistance in localising the accessory pathways with reasonable accuracy by application of specific algorithms. This case emphasises the appropriate pathway localisation and occasional need for resorting to CS angiography to expose a congenital anomaly such as CS diverticulum. Pre-excitation in CS diverticulum is attributed to a complex anatomic arrangement and abnormal extension of the CS myocardial coat to the left ventricular epicardium. ${ }^{4}$

\section{Anishkumar Nair, Kader Muneer, Chakanalil Govindan Sajeev}

Department of Cardiology, Government Medical College, Kozhikode, Kerala, India

Correspondence to Dr Anishkumar Nair, Department of Cardiology, Government Medical College, Medical College Road, Kozhikode, Kerala 673008, India; dr.anish84@gmail.com

Contributors KM: substantial contributions to the conception, design of the work, the acquisition, analysis and interpretation of data. AN: drafting the work and revising it critically for important intellectual content. CGS: final approval of the version published. All authors have an agreement to be accountable for all aspects of the work in ensuring that questions related to the accuracy or integrity of any part of the work are appropriately investigated and resolved.

Competing interests None declared.

\section{Patient consent Obtained.}

Provenance and peer review Not commissioned; externally peer reviewed.

- Additional material is available. To view please visit the journal online (http://dx. doi.org/10.1136/heartasia-2016-010741).

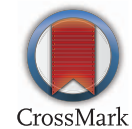

To cite Nair A, Muneer K, Sajeev CG. Heart Asia 2016;8:60-61. doi:10.1136/ heartasia-2016-010741

Heart Asia 2016;8:60-61. doi:10.1136/heartasia-2016-010741

\section{REFERENCES}

1 Sun Y, Arruda M, Otomo K, et al. Coronary sinus-ventricular accessory connections producing posteroseptal and left posterior accessory pathways: incidence and electrophysiological identification. Circulation 2002;106:1362-7.

2 Chatterjee K. Cardiology. New Delhi: Jaypee Brothers Medical Publisher, 2013:673.

3 Chesler E, Chesler E. Clinical cardiology. New York: Springer-Verlag, 1993:99.

4 Jang SW, Rho TH, Kim DB, et al. Successful radiofrequency catheter ablation for Wolff-Parkinson-White syndrome within the neck of a coronary sinus diverticulum. Korean Circ J 2009;39:389-91. 